\title{
Surface features of utterances, credibility judgments, and memory
}

\author{
YASUHIRO OZURU \\ University of Memphis, Memphis, Tennessee \\ and \\ WILLIAM HIRST \\ New School University, New York, New York
}

\begin{abstract}
Information acquired in conversation is often not credible, which makes monitoring its credibility critical. Listeners of conversations often use surface features of utterances, such as pause and intonation, to guide their credibility judgments. In this research, we explore whether listeners' delayed credibility judgments about remembered information are affected by the surface features of the speakers' utterances. In addition, we examine some of the specific factors involved in this issue: (1) how listeners' listening strategies influence their subsequent credibility judgments and (2) how the type of surface features of the utterances influences listeners' ability to make delayed credibility judgments. The results indicate that intonation of the utterances continues to influence listeners' assessment of the credibility of remembered information, that the influences of intonation depend on listening strategies, and that people have difficulty using/remembering pause length when making a delayed credibility judgment. The implications of these findings are discussed.
\end{abstract}

Although speakers usually follow the cooperative principle during conversation (Grice, 1975), they sometimes violate it and provide erroneous information. For example, a neighbor may tell his or her friends about a new neighbor's job even when he or she does not clearly remember what the neighbor does. Knowing this, listeners may often monitor the credibility of a speaker's utterances. Our concern here is not with judgments about whether a speaker is lying but, rather, whether a speaker is failing to capture accurately the content of the original material or event.

Although a small body of literature has explored how listeners monitor the credibility of information as they listen to other people's speech (e.g., Brennan \& Williams, 1995; Fox Tree, 1999; Kraut, 1978; Streeter, Krauss, Geller, Olson, \& Apple, 1977), little research had been conducted on the credibility judgments listeners may make after the fact - that is, not as someone is speaking, but hours or days later, as they think back on the conversation. Imagine a juror in a trial whose judgment about the credibility of a witness's testimony is critical. In some cases, credibility judgments may be made as a witness is

The study described in this article was conducted as the first author's $\mathrm{PhD}$ dissertation research. Support from NIMH Grant MH066972 is gratefully acknowledged. We thank Susan Brennan and Michael Schober, as well as Shari Speer and two anonymous reviewers, for helpful comments and feedback on the earlier draft of the article. We also thank Robert Meksin and Nimali Jayasinghe for helping to construct the stimulus materials. Correspondence concerning this article should be addressed to Y. Ozuru, Department of Psychology, University of Memphis, 202 Psychology Bldg., Memphis, TN 38152-3230 (e-mail: y.ozuru@, mail.psyc.memphis.edu). testifying, but in other instances, a juror may become concerned about the credibility of a witness's account only as he or she deliberates in the jury room. Such retrospective credibility judgments have yet to be explored.

There are several ways in which listeners can make delayed credibility judgments. They can rely on their own general knowledge about the topic of the remembered information, assess the general difficulty of the topic for an average person, or consider previous experiences with the speaker on a similar topic. Alternatively, they can make the delayed credibility judgments on the basis of the features of a witness's utterance. The latter possibility is worth exploring because listeners appear to use such features as pause length and intonation to make credibility judgments as they listen to speech (Brennan \& Williams, 1995). For the purpose of this article, we will refer to these features of utterances collectively as surface features.

Delayed credibility judgments based on surface features can be made in two ways. Listeners may store meaning (e.g., credibility, speaker's certainty, etc.) of the surface features as a part of the interpretation of the utterance, and this stored representation of the credibility may guide their delayed credibility judgments. Alternatively, listeners can directly remember the surface features (i.e., intonation and pause) themselves and derive the delayed credibility judgment from these remembered features.

Specific questions we explore here include the following. (1) To what extent do listeners' delayed credibility judgments on remembered information reflect these surface features of utterances? (2) If they do, are listeners' judgments more likely to be based on remembered credibility judgments and/or remembered surface features 
themselves? (3) How do the specific surface features, such as intonation or pauses, and the listeners' goal of listening to the utterances influence their delayed credibility judgments based on these surface features?

\section{Surface Features and Assessment of Credibility}

Speakers' use of surface features. Answering a question involves searching for information for an answer, monitoring whether the answer is correct or desirable, and producing an overt response (Smith \& Clark, 1993). Speakers' behaviors should reveal problems experienced at any of these question-answering stages. An extended pause before producing an answer may reveal that speakers are having trouble finding an answer. People also will spend a longer time deciding whether to report an answer when they are not confident about the retrieved information (Koriat, 2000). Thus, a long pause before an answer can also reveal problems in the formulation and postretrieval monitoring of an answer. In addition, at the stage of response production, a speaker may purposefully display production difficulties. Smith and Clark showed that speakers use fillers (such as $u h$ and $u m$ ) to signal that they are searching for an answer when a long delay is anticipated. Speakers appear to anticipate a delay on the basis of a feeling of knowing (FOK). FOK refers to people's ability to make a prospective judgment on whether they are likely to retrieve the target information (Nelson \& Narens, 1990). There have been several processing models proposed to account for this ability (see Schwartz, 1994, for a review of theories and experiments on FOK). Reder (1987) showed that subjects could make will know (FOK) judgments more quickly than do know (whether they actually know the information) judgments, without cost in accuracy, establishing that people can make accurate judgments on whether they know an answer without actually examining their success at retrieving the target information.

Intonation is another device that speakers may use to signal their confidence in an answer. According to Grice (1975), speakers in conversation observe a maxim of quality that states "do not say that for which you lack adequate evidence." So, when speakers are not certain about an answer, they should signal the uncertainty, lest listeners would assume that they are certain. Bolinger (1989) suggests that uncertainty can be signaled with rising intonation (see also Pitrelli, Beckman, \& Hirschberg, 1994, for a more specific classification system of intonation). Indeed, Smith and Clark (1993) showed that an answer with rising intonation was more likely to be incorrect than an answer with falling intonation.

Listeners' use of surface features. Brennan and Williams (1995) showed that listeners of factual questionanswering exchanges were sensitive to the nature of between-speaker pauses (i.e., the length and the presence of fillers such as ums or $u h \mathrm{~s}$ ) and intonation (rising vs. falling) when making feeling of another person's knowing (FOAK) judgments immediately after hearing the exchanges. In essence, a FOAK judgment of an answering response is a credibility estimation of an answer.
Kraut (1978) also has demonstrated that listeners use a pause between a question and an answer to judge the truthfulness of the answer by having participants listen to different versions of a tape-recorded job interview. This study indicated that a long pause before the self-serving answer magnified the suspicion (perception of deceptive intentions) of the participant. Along the same line, Fox Tree (1999) has shown that people listening to but not directly involved in a conversation (overhearers) were sensitive to pauses and $u m \mathrm{~s}$ in a conversational turn when assessing the second speaker's familiarity with the first speaker and the second speaker's production difficulty, deceptive intention, and comfort with the topic. Finally, Barr (2003) has shown that paralinguistic cues, such as intonational contour and filled pauses, influence listeners' learning of novel categories. Learners who heard surface feature cues consistent with the structure of the underlying categories showed better learning. However, none of this work has explored whether the surface features of speech continue to influence a listener's credibility judgments of utterances after a delay.

\section{Memory for Conversations: Credibility Judgments and Surface Features}

Listeners' delayed credibility judgment could be influenced by the surface features of the utterances in two different ways: (1) by remembered credibility judgments made while listening to the speech or (2) by remembered relevant surface features themselves.

Although no empirical study has directly examined people's remembrance of credibility judgments, the literature on eyewitness suggestibility indicates that the credibility of the source will influence the extent of the misleading information effect (e.g., Dodd \& Bradshaw, 1980; Echterhoff, Hirst, \& Hussy, 2005). The influence of credibility, however, varies with delay: The effect of postevent misinformation from a low credibility source increases with the delay between study and test (Underwood \& Pezdek, 1998). This sleeper effect (Hovland, Lumsdaine, \& Sheffield, 1949) suggests that credibility information may be available for only a short time.

As for the memory of surface features of speech, recent research has revealed that people remember far more of the surface characteristics of speech than earlier work suggested (e.g., Anderson, 1974; Bransford, Barclay, \& Franks, 1972; Gernsbacher, 1985), especially if they view the information as important (Holtgraves, 1997; Keenan, MacWhinney, \& Mayhew, 1977; Murphy \& Shapiro, 1994). Keenan et al., for instance, found that an audience in a seminar could remember the verbatim wording of some sentences 27 and $48 \mathrm{~h}$ later.

Moreover, research with a single-word recognition technique has indicated that some voice information is available for explicit or conscious recollection. Bradlow, Nygaard, and Pisoni (1999) showed that people can explicitly discriminate whether words have been presented with the same voice, at the same speed, and/or with the same amplitude. Dodson and colleagues (Dodson, Holland, \& Shimamura, 1997; Dodson \& Shimamura, 2000) 
showed that people remember the voice by which an item was presented, using a source-monitoring task (Johnson, Hashtroudi, \& Lindsay, 1993).

People can also remember detailed prosodic features of music in memory. For example, music listeners are able to identify a particular performance from similar performances that retain the same melodic and rhythmic structure but differ in expressive features (Palmer, Jungers, \& Jusczyk, 2001). Other research indicates that the prosodic feature of speech is, at least, stored as an implicit form of memory (Roediger \& Blaxton, 1987; Schacter, 1987). For instance, Speer, Crowder, and Thomas (1993) examined listeners' implicit memory of prosodic structures (stress and prosodic boundary), using contextual facilitation of prosody for subsequent recognition of spoken sentences. They found that listeners' recognition ratings were higher if the sentences had been spoken with the same prosody at initial presentation and test than if they had been presented with different prosody. Importantly, the benefit of matching did not differ between sentences whose prosody biased listeners toward different syntactic analysis and sentences whose prosody affected only changes of focus. Furthermore, the same effect of matching was found for nonsense sentences. Finally, more recent research has indicated that speakers' production is influenced by the prosody and syntax of sentences that they hear prior to speaking (Jungers, Speer, \& Palmer, 2002). These studies suggest that the prosodic features of spoken sentences are stored and available at least as an implicit form of memory (e.g., contextual facilitation), even when the listeners did not pay specific attention to the prosody at the time of listening to the utterances.

As for speech disfluency, although there is growing evidence that disfluency, such as pauses (filled or unfilled), false starts, and repetition, influences listeners' comprehension process for the utterances (e.g., Arnold, Fagnano, \& Tanenhaus, 2003; Bailey \& Ferreira, 2003; Brennan \& Schober, 2001; Fox Tree, 2001), its influence on metalinguistic aspects of processing (e.g., FOAK judgments) appears to be limited to instances in which the task itself directs listeners' focus onto them (e.g., Brennan \& Williams, 1995; Kraut, 1978). By and large, listeners have a difficult time noticing fillers such as $u m$ s and $u h$ s (Christenfeld, 1995; J. Lindsay \& O'Connell, 1995; Martin, 1971; Martin \& Strange, 1968; Shriberg \& Lickley, 1992), unless they are explicitly asked to attend to the style of the speech (Christenfeld, 1995). These findings suggest that disfluencies may be stored only under certain listening conditions.

\section{Present Experiments}

The aim of this study was twofold. First, we examined whether listeners would continue to show sensitivity to the surface features when they were asked to rate the credibility of the utterances after a delay. Given the effect of intonation and pause length found for immediate FOAK judgments (Brennan \& Williams, 1995) and the influence of credibility of the source on the subsequent false recognition of misleading information (e.g., Underwood \& Pez- dek, 1998), we expected that listeners' delayed credibility judgments would be influenced by the surface features of the utterances. In particular, assuming that both specific surface features (e.g., intonation) and abstract judgments are encoded as part of a person's memory representation when he or she listens to utterances with a concern about credibility, the influence of the surface features on the subsequent delayed credibility judgments should be stronger when listeners listen to utterances with such a concern.

Second, we examined listeners' ability to explicitly or consciously access stored prosodic features (i.e., intonation) of speech and to use this information for delayed credibility judgments of information remembered from utterances. Making delayed credibility judgments on the basis of the intonation of spoken sentences requires conscious access to the stored representation of intonation of the utterances, as opposed to implicit memory (Roediger \& Blaxton, 1987; Schacter, 1987). This may especially be the case when listeners hear utterances without anticipating that they will need to make an FOAK or credibility judgment later. Under this circumstance, listeners will be unlikely to make online credibility judgments as they listen to an utterance and, hence, will be unlikely to store the credibility of the utterances so that it can be used for delayed credibility judgments. We expected to find a different pattern of results for listeners' use of intonation and pause for delayed credibility judgments, given the differences reported in the literature on listeners' processing of prosodic information (e.g., Speer et al., 1993) and on disfluencies (e.g., Christenfeld, 1995); that is, listeners' delayed credibility judgments should show selective sensitivity to intonation, but not to the pause length, when they heard original utterances without a concern for its credibility.

We conducted three experiments in order to address the issues above. Experiment 1 replicated Brennan and Williams's (1995) study. In Experiment 2, we examined listeners' sensitivity to the pause length of answers (unfilled pauses) and to intonation when they made credibility judgments after a delay. In Experiment 3, we further examined the nature of memory underlying delayed credibility judgments with two-alternative forced choice memory judgment tasks.

\section{GENERAL METHOD}

All the experiments in this article used the same stimulus materials, with minor modifications. The stimuli were recorded question-answer exchanges between two people. We selected four articles from 6-month-old editions of The New York Times and modified the details to generate question-answer scripts. The specific content of the articles was modified so that the participants' FOAK judgments would not be influenced by the memory of the content of the actual articles, even when they had read the articles. These articles described the following: (1) a highway traffic accident, (2) a man who was about to become a lawyer even though he had a criminal record for murder, (3) a financial crisis of a family resulting from the father's 
sudden illness, and (4) a new priest in the church and his career history.

Fifty-two question-answer scripts were constructed on the basis of these articles (16 items from each of the three articles and 4 items from the first short article). Of these, 36 items (12 from each of the three longer articles) were used as test items. With regard to the remaining 16 items, 12 items were used as fillers to manipulate the listeners' goal in Experiments 2 and 3, and 4 items were used as practice items.

The question-answer scripts were designed to satisfy three constraints. First, the answers were specific to the content of the articles, so that the participants could not estimate the credibility of the answers on the basis of general knowledge. Second, the answer to a question could be provided in a few words, rather than a complete sentence. This was necessary to standardize the intonation of the answers. Third, the content of each item was independent from that of the other items, so that exposure to one item would not influence the participants' FOAK judgments of other items. Examples of the questions and answers used in the experiment appear in Appendix A.

Two people recorded the questions and answers separately onto an analog audiotape, using a portable tape recorder. A female native English speaker recorded the questions, reading from a script. She was instructed to speak like an experimenter administering recall tests to a participant. After several trials, the speaker and experimenter chose questions on the basis of the quality of speech and recording and digitized them onto a Macintosh computer; the same computer was used throughout the study.

A professional male actor recorded the answers in order to maximize the quality of the stimulus answers (henceforth referred to as performed answers). In the recording sessions, the first author asked questions, and the actor answered the questions on the basis of the scripts. Before each exchange, he was told to respond either with confidence or with a lack of confidence. In doing so, he was instructed to use either falling or rising intonation to convey either confidence or a lack of confidence, respectively. The entire session was recorded on an audiotape. Recording sessions were repeated until both the experimenter and the actor judged that there were several good answers with both falling and rising intonation for each item. The experimenter digitized the best answers on a computer. Selection of the answers was based on discussions between the actor and the experimenter about the performance and recording quality. For example, we excluded answers with overly exaggerated intonation. Fillers such as $u m$ s and $u h$ s were digitally removed by using SoundEdit 16, Version 2.

We digitally combined four different answers to each question. The four answers were constructed by combining two different types of intonation (rising and falling) with two pause lengths, producing (1) answers with falling intonation following a short (1-sec) pause, (2) answers with rising intonation following a 1-sec pause, (3) answers with falling intonation following a long (5-sec) pause, and (4) answers with rising intonation following a 5-sec pause. Pause length was varied by digitally inserting either a 1 -sec or a 5-sec period of silence between a question and its answer. In digitally combining the question, pause, and answer portions of the recording, we made sure that the naturalness of the question-answer exchanges was preserved by carefully following Brennan and Schober's (2001) method. For example, to make sure that the question, pause, and answer portions of the recording sounded continuous, we recorded the answers, questions, and periods of silence that filled in the intervals in the same room.

We constructed four stimulus lists (A, B, C, and D), so that a particular item appeared once per list, spoken with different intonations following either a long or a short pause. The pairings between the four types of surface features and the 36 item types were fully counterbalanced. Each stimulus list contained 39 items (36 test items and 3 practice items). The stimulus lists were programmed using the SuperLab program.

A stimulus presentation program consisted of the instructions, a heading for each of the four stimulus blocks (one practice block and three test blocks, corresponding to the four newspaper articles from which the questionanswer exchanges were constructed), and the stimulus conversations in the blocks. The practice block contained 3 question-answer exchanges, and each test block contained 12 exchanges. The heading provided the topic of the question-answer exchanges of that block (e.g., highway traffic accident).

Half the test items in each of the three test blocks were spoken with rising intonation, and the other half with falling intonation; half were spoken with a short pause, and the other half with a long pause. Thus, there were three test items for a particular paralinguistic feature type in each block, making up a total of nine items for a particular surface feature type in the entire test. Three practice items covered three surface feature types (rising answer with a long pause, falling answer with a short pause, and falling answer with a long pause).

\section{STIMULUS PRETEST}

We tested whether the performed answers sounded natural enough to the listeners, in comparison with spontaneous answers (henceforth called spontaneous answers). These spontaneous answers were solicited prior to the recording session of the performed answers from the same actor. In this earlier session, the experimenter asked questions about the articles to the actor after he had read the articles very briefly. The questions were similar to those in the stimulus exchanges. The actor produced 25 spontaneous answers. Two independent judges classified these answers into two classes (rising and falling intonation). The judges agreed that 15 of them were with falling intonation and 10 of them were with rising intonation.

We presented the actor's 25 spontaneous answers, together with the performed answers, to 15 native English speakers and asked them to rate whether they believed that the answers were spontaneous. There were 75 performed items (the 72 target items and the 3 practice items) and 
25 spontaneous utterances. The participants judged the degree to which each answer sounded spontaneous on a 7 -point scale. They received $\$ 3$ each for participating. Each answer was played once in a different random order for each listener through stereo headphones. After each answer, the listeners took as much time as necessary to make the rating, with 1 labeled performed, 4 with question marks, and 7 labeled spontaneous. Care was taken to explain what was meant by performed and spontaneous, with the instructions, "Some of the answers were performed based on a written script while other answers were collected from spontaneous question-answer exchanges." Table 1 presents the participants' ratings of the spontaneity.

Following Brennan and Schober's (2001) method, we used a $t$ test to examine whether the listeners could distinguish between performed and spontaneous answers. In the statistical analyses of this article, both participant-based $\left(t_{1}\right.$ or $\left.F_{1}\right)$ and item-based $\left(t_{2}\right.$ or $\left.F_{2}\right)$ analyses will be reported whenever appropriate. As can be observed in Table 1, the ratings on the spontaneity of an utterance did not differ across utterance types, indicating that there is no evidence that the listeners detected the difference between the spontaneous and the performed answers $[t(15)=1.12$, n.s.]. This was true for utterances with falling intonations $\left[t_{1}(15)=\right.$ 0.18 , n.s.; $t_{2}(51)=0.15$, n.s.] and for utterances with rising intonation $\left[t_{1}(15)=1.49\right.$, n.s.; $t_{2}(45)=0.51$, n.s.].

\section{EXPERIMENT 1}

Experiment 1 was a replication of Brennan and Williams's (1995) study, designed to determine whether our stimuli would produce the same results as the stimulus materials used by Brennan and Williams, which involved questions purposefully made as content free as possible, in order to prevent the listeners from relying on their own general knowledge. For example, the questions soliciting the answer "Orwell" was "What is the answer to Question 5?" In the present study, we used questions that more closely specified the details of information requested (e.g., Q: What kind of car was the criminal driving at the time? A: A Ford). This change made the present stimuli more meaningful.

\section{Method}

Participants. Twenty native English speakers, recruited by flyers posted on the New School University campus, participated in the study. They received $\$ 4$ each for participating.

Design and Materials. The stimulus materials were performed question-and-answer exchanges, as described in the General Method section.

Table 1

Stimulus Answers: Ratings on the Degree of Spontaneity (1, Performed; 7, Spontaneous)

\begin{tabular}{lccccc}
\hline & \multicolumn{2}{c}{ Performed } & & \multicolumn{2}{c}{ Spontaneous } \\
\cline { 2 - 3 } \cline { 5 - 6 } Origin of the Answer & $M$ & $S D$ & & $M$ & $S D$ \\
\hline Falling intonation & 4.34 & 1.52 & & 4.36 & 1.48 \\
Rising intonation & 3.94 & 1.16 & & 4.09 & 1.05 \\
$\quad$ Total & 4.14 & 0.88 & & 4.26 & 0.88 \\
\hline
\end{tabular}

Procedure. The participants were tested individually. Each participant was randomly assigned one stimulus list (A, B, C, or D). In the instructions preceding the stimulus presentation, the participants were told to listen carefully to the recordings of question-answer exchanges about the content of the newspaper articles and, for each answering response, estimate how likely it was that the respondent knew the correct answer, on a 7-point scale.

The experimenter supplemented the instructions when requested. However, the experimenter was careful not to provide any direction on how the participants should make the estimation. After the instructions, the participants hit any key to begin the task. As soon as the participants hit a key, a heading (e.g., the following exchanges are about a highway traffic accident) appeared on the screen, and it remained there for $10 \mathrm{sec}$. The presentation of stimuli began $1 \mathrm{sec}$ after the heading had disappeared. The experimenter left the room to let the participants perform the task alone at this point. The following response probe was displayed on the screen during the presentation of each question-answer sequence. The probe disappeared once the participants had hit an appropriate number key to indicate their response:

Do you think this was the correct answer to this question?

$$
\begin{array}{ccccccc}
1 & 2 & 3 & 4 & 5 & 6 & 7 \\
<<\text { definitely incorrect } & & & \multicolumn{2}{l}{\text { definitely correct }>>}
\end{array}
$$

The computer presented the next item $1 \mathrm{sec}$ after receiving the rating response. The participants performed the task at their own pace. Presentation order of the items, except for the first item, was randomized within each block, but the order of the blocks was constant. The first item was always placed at the beginning, because it introduced the main character of the topic in that block. After the task, the participants were debriefed, paid, and dismissed. None of the participants found the task difficult.

\section{Results and Discussion}

The overall results replicated Brennan and Williams's (1995) findings. Both pause length and intonation affected the listeners' FOAK ratings, as is shown in Figure 1. Answers with falling intonation were rated higher than answers with rising intonation $\left[t_{1}(19)=8.66, p<\right.$ $\left..001 ; t_{2}(35)=14.86, p<.001\right]$, whereas answers with short pauses were rated higher than answers with long pauses $\left[t_{1}(19)=10.56, p<.001 ; t_{2}(35)=8.70, p<\right.$ $.001]$. The interaction between intonation and pauses was significant $\left[F_{1}(1,19)=74.88, M S_{\mathrm{e}}=1.160, p<.001\right.$; $\left.F_{2}(1,35)=17.04, M S_{\mathrm{e}}=0.315, p<.001\right]$, indicating that the listeners' sensitivity to intonation was more pronounced for answers with short pauses than for answers with long pauses.

The results of this experiment extend those of Brennan and Williams (1995) by establishing that participants' FOAK judgments are sensitive to the surface features of utterances, even when the stimulus exchanges have specific meaningful content.

\section{EXPERIMENT 2}

Experiment 2 addressed three questions. First, when participants remember the gist of a response to a question, will participants' credibility judgments about remembered responses continue to be influenced by the surface features of the response? Second, will participants' ability to remember a response and make a FOAK judgment depend 


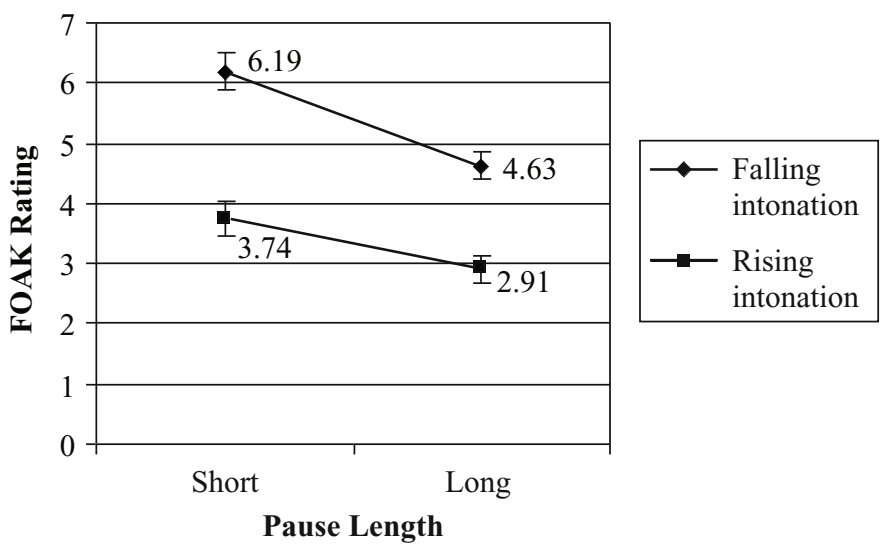

Figure 1. Feeling of another person's knowing (FOAK) ratings for answers with rising intonation and falling intonation as a function of short (1-sec) and long (5-sec) pauses.

on how they initially listened to the conversation? Third, what might be the processes by which listeners perform delayed credibility judgments based on the paralinguistic features? To examine these questions, we presented the question-answer exchanges tested in Experiment 1 to the participants under three conditions: FOAK task, paraphrasing task, and no task. In the test phase, the participants read a paraphrase of each question-answer exchange in a text form and were asked (1) whether they remembered the information from the exchanges and (2) when they remembered the information, how they would judge the credibility of the information.

\section{Method}

Participants. Sixty native English speakers participated in the experiment. Some of the participants were recruited by flyers posted on the New School University campus, and others through an ad posted on a free Internet site. They received a payment of $\$ 6$ each for participation. They were randomly assigned to the three conditions. None of the participants had participated in Experiment 1. The data of 5 participants were discarded and replaced with new participants' data for these reasons: One participant (in the FOAKfocus condition) did not follow the instructions, and the recognition performance of 4 participants ( 3 in the paraphrasing and 1 in the no-task conditions) was at least two standard deviations below the mean of the other participants.

Design and Materials. Two within-subjects factors and one between-subjects factor were manipulated. The within-subjects factors were intonation type and pause length (as in Experiment 1). The between-subjects factor was the study condition, with an equal number of participants in each condition. The stimuli were the same as those used in Experiment 1, with two modifications. First, we reduced the number of test blocks to two from the original three because, in pilot work, we discovered that the participants found it difficult to maintain their attention with three blocks. As a consequence, the stimuli consisted of one practice block and two test blocks, with a total of 36 items ( 3 practice items and 1 filler item in the practice block and 12 target and 4 filler items for each of the two test blocks). Second, we added 9 filler items, 4 for each of the two test blocks and 1 for the practice block. The four fillers in each test block covered the four combinations of the two paralinguistic features we were interested in: pause and intonation. The fillers added to the practice block had different paralinguistic features from the three practice items. The filler items had a 500-msec length tone following a 500-msec delay after the question-answer exchange. Intervals between each item were set at $8 \mathrm{sec}$. The presentation order of target and filler items was randomized within each block.

Depending on condition, the participants were instructed to listen to the question-answer exchanges with the expectation that they would have to (1) make FOAK judgments or (2) paraphrase the exchange. In the no-task condition, the participants were not told how to listen to the exchange. The participants had to make the required judgments only on those items that ended with the tone (i.e., the filler items). In this way, we could control the participants' listening strategies for the target without requiring them to perform an overt response to the target items.

For the test phase, we constructed a questionnaire soliciting delayed credibility and yes/no recognition judgments. The questionnaire contained a total of 39 recognition probes ( 3 practice items and 36 test items). Of the 36 test items, 24 were targets, and 12 were lures. These recognition probes were presented in text form. A question and its answer were combined to make a target statement. For example, "Q: When did he commit the murder? A: 25 years ago" was combined to make a target statement, "He committed the murder 25 years ago." We presented a paraphrase of question-answer exchanges in a text form, rather than repeating the original questionanswer exchange, in order to prevent the participants from relying on the familiarity or automatic influence that a repetition might have elicited (Jacoby, 1991). A native English speaker checked the recognition probe to make sure that each statement captured the gist of the target conversation (see Appendix B). Thirteen lure statements were also constructed, six for each of the two test blocks and one for the practice block. The lure expressed information that was not mentioned in the original question-answer exchanges but could have reasonably been in the exchanges.

Each target statement was presented with a written question "Do you remember this information from the conversation you heard earlier?" and with response options, "If you remember the information press the Y key, and if you do not remember the information, press the N key." The computer displayed the prompt for a delayed FOAK judgment as soon as the participants pressed the $\mathrm{Y}$ or the $\mathrm{N}$ key. The prompt consisted of a target statement, a 7-point FOAK scale (the one used in Experiment 1), and a question: "Do you think this information accurately reflects the content of the newspaper article that the respondent of the conversation read?"

Procedure. The presentation phase in Experiment 2 was identical to that in Experiment 1, except for the variation in the study conditions and corresponding instructions. The instructions in the FOAK 
condition stated that the experimenter was interested in their skill at estimating whether the respondent of question-answer exchanges knows the correct answer. The participants were asked to write down a subjective estimate of how likely it was that the respondent knows the correct answer for each answering response. The instructions in the paraphrasing condition stated that the experimenter was interested in their comprehension of and paraphrasing skills for the question-and-answer dialogues. They were asked to write down the gist of the information discovered from the dialogue on the sheet of paper provided by the experimenter. The participants in the FOAK and the paraphrasing conditions were also told that they had to write down the estimate (or paraphrase) only when the respondent's answer was followed by a tone. The instructions in the no-task condition asked the participants to listen to the dialogues very carefully. They were also asked to disregard the occasional tone, which was to manipulate orienting tasks for the other two conditions. The participants were not informed about a task they were to perform later.

The test phase began immediately after the completion of the presentation phase. The presentation order of the items was randomized within a block, whereas the test blocks were presented in the same order as the stimulus presentation. First, the participants read general instructions presented on the computer screen in the presence of the experimenter. The instructions stated that they would be asked (1) to indicate, for each statement, whether they remembered the information in the statement from question-answer exchanges they had heard earlier and (2) to estimate, for information that they remembered from the exchanges, the degree to which the information accurately reflected the content of the newspaper article that the respondent of the conversation had read. Reading the instructions and clarifying the participants' questions took 3-5 min. The participants performed the task alone. After the test, the participants were debriefed, paid, and dismissed.

\section{Results and Discussion}

There are two main results to be reported: The first section will present the participants' item recognition performance, and the second section their delayed credibility judgment performance. We did not analyze the data of FOAK estimation and paraphrasing collected for the filler items, although we checked them to assess whether the participants had followed instructions.

Item recognition performance. We computed each participant's hit rates (proportion of yes responses to the target items) and false alarm rates (proportion of yes responses to lure items) and the corrected score (subtracting false alarm rates from hit rates). A one-way ANOVA indicated that the study conditions had significant influences on the participants' recognition memory $[F(2,57)=$ 17.23, $\left.M S_{\mathrm{e}}=0.0281, p<.001\right]$. Item-based statistical analysis could not be performed, because lure items were not counterbalanced. A post hoc analysis indicated that the participants' recognition performance was significantly better in the paraphrase condition $[M=.70$, $\left.S D=.14 ; F(1,38)=24.98, M S_{\mathrm{e}}=0.0240, p<.001\right]$ and the no-task condition $[M=.75, S D=.19 ; F(1,38)=$ $\left.25.69, M S_{\mathrm{e}}=0.0326, p<.001\right]$ than in the FOAK condition $(M=.46, S D=.17)$. The performance did not differ between the paraphrase and the no-task conditions $[F(1,38)<1]$. Finally, a one-way ANOVA on false alarm rates indicated a nonsignificant effect of study condition $\left[F(2,57)=1.72, M S_{\mathrm{e}}=0.0240, p>.1\right]$, suggesting that the participants' decision criteria did not differ between the study conditions. These results suggest that listening to question-answer conversations with a concern about FOAK decreased the accuracy of the participants' recognition memory of the contents of the exchanges. However, the participants' recognition performance in the FOAK condition was significantly above chance level, as indicated by a one-sample $t$ test $[t(19)=12.129, p<.001]$. This result shows that the participants understood and retained information from the exchanges even when focusing on the FOAK condition.

Delayed credibility judgments. We examined the participants' delayed credibility ratings for items for which the participants claimed to recognize the item. All the participants remembered some items in each of the four item categories (rising-short/long, falling-short/long). Figure 2 shows the effects of intonation and pause length on the participants' delayed credibility ratings in the three study conditions.

A 2 (rising vs. falling intonation) $\times 2$ (long vs. short pauses) $\times 3$ (study condition) ANOVA indicated that the participants' overall delayed credibility rating was significantly higher for falling $(M=5.95)$ than for rising $(M=5.30)$ intonation $\left[F_{1}(1,57)=30.57, M S_{\mathrm{e}}=0.825\right.$, $\left.p<.001 ; F_{2}(1,20)=14.23, M S_{\mathrm{e}}=1.187, p<.01\right]$. The main effect of study condition was also significant, showing that the participants' overall delayed FOAK rating was lower in the FOAK condition $(M=4.87)$ than in the paraphrase $(M=5.84)$ and no-task $(M=6.13)$ conditions $\left[F_{1}(2,57)=14.58, M S_{\mathrm{e}}=2.479, p<.001 ; F_{2}(2,40)=\right.$ $\left.52.55, M S_{\mathrm{e}}=0.802, p<.001\right]$. Ratings did not differ between long $(M=5.59)$ and short $(M=5.67)$ pauses $\left[F_{1}(1,57)<1 ; F_{2}(1,20)=1.315, p>.2\right]$. The interaction between intonation and study condition was significant by participants $\left[F_{1}(2,57)=3.39, M S_{\mathrm{e}}=0.825, p<.05\right]$, but not by items $\left[F_{2}(2,40)=1.71, p=.2\right]$, suggesting that the participants' sensitivity to intonation in the delayed credibility judgments was somewhat affected, but not critically, by study conditions. Finally, the interaction between pause length and study condition was marginally significant in both participant-based and item-based analyses $\left[F_{1}(2,57)=2.72, M S_{\mathrm{e}}=0.291, p=.06 ; F_{2}(2,40)=2.97\right.$, $\left.M S_{\mathrm{e}}=0.565, p=.06\right]$.

We further analyzed the participants' delayed credibility rating separately for each study condition, in order to explore whether the participants might be performing the judgments in different ways as a function of condition. The ratings were consistently higher for falling than for rising intonation in the FOAK $\left[F_{1}(1,19)=14.569, M S_{\mathrm{e}}=\right.$ $\left.1.550, p<.01 ; F_{2}(1,20)=6.057, M S_{\mathrm{e}}=1.520, p<.05\right]$, paraphrase $\left[F_{1}(1,19)=4.818, M S_{\mathrm{e}}=0.466, p<.05\right.$; $\left.F_{2}(1,23)=4.698, M S_{\mathrm{e}}=0.518, p<.05\right]$, and no-task $\left[F_{1}(1,19)=13.037, M S_{\mathrm{e}}=0.460, p<.01 ; F_{2}(1,23)=\right.$ $\left.14.156, M S_{\mathrm{e}}=0.458, p<.01\right]$ conditions. In contrast, there was no significant difference in the rating between the short and the long pauses in the FOAK $\left[F_{1}(1,19)=\right.$ $\left.1.178, p>.2 ; F_{2}(1,20)=1.072, p>.3\right]$ and paraphrase $\left[F_{1}(1,19)=2.332, p>.1 ; F_{2}(1,23)=1.630, p>.2\right]$ conditions.

As for the no-task condition, long pauses were rated reliably higher $(0.24)$ than short pauses $\left[F_{1}(1,19)=8.362\right.$, 

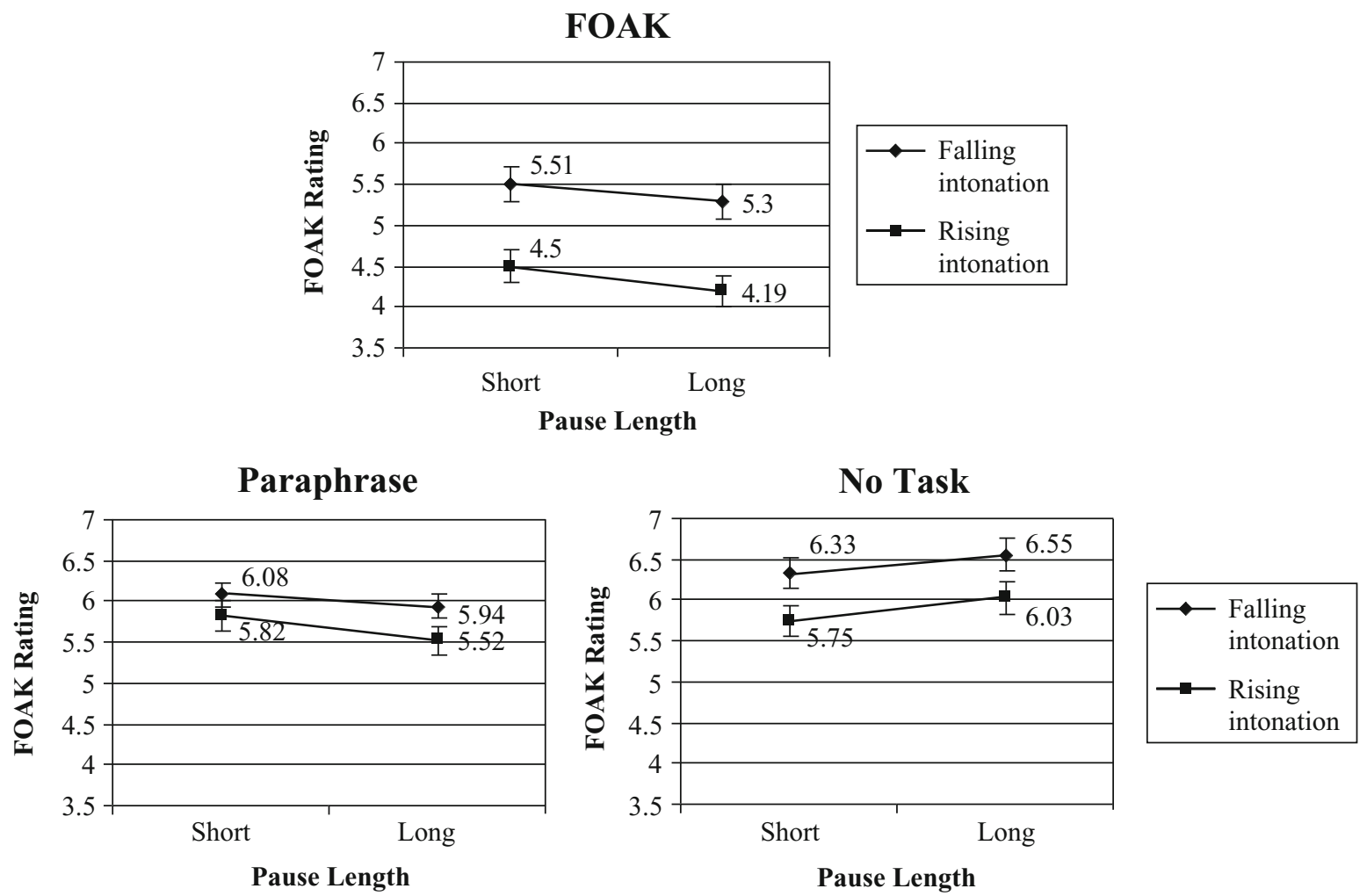

Figure 2. Effects of intonation and pause length on feeling of another person's knowing (FOAK) ratings in the three study conditions.

$M S_{\mathrm{e}}=0.152, p<.01 ; F_{2}(1,23)=3.322, M S_{\mathrm{e}}=0.358$, $p=.08]$. For this reversed effect of pause in the no-task condition, we cannot provide any specific interpretation from the data; the data just failed to show evidence of the participants' systematic sensitivity to pause length, such as the one observed in Experiment 1.

There are four main conclusions from these analyses. First, the participants appeared to remain sensitive to intonation when estimating the credibility of remembered information after a significant delay (longer than $10 \mathrm{~min}$ ). Second, they were more suspicious (or cautious) about the credibility of remembered information when they heard the information with a concern about FOAK than when they heard the conversation without the concern. This effect could be partly attributable to several participants who gave a 7 (maximum score) to all the items (3 participants in the paraphrasing condition and 3 participants in the notask condition). Yet the effect remained significant even after excluding these participants' data from the analysis $\left[F_{1}(2,52)=11.443, M S_{\mathrm{e}}=2.255, p<.001 ; F_{2}(2,19)=\right.$ $\left.34.151, M S_{\mathrm{e}}=0.877, p<.001\right]$. One might raise a concern that these participants with extreme responses were not making a good-faith effort. We, however, did not exclude the data of these participants from the overall analyses, because their recognition performance was within the normal range, an evidence of making a good-faith effort.

Third, the participants' sensitivity to intonation after a delay appeared to decline marginally in the paraphrasing and the no-task conditions, in comparison with the FOAK condition. Fourth, contrary to our expectation, there was no evidence of the participants' sensitivity to pause length in the delayed credibility judgments even in the FOAK condition. The relatively consistent sensitivity to intonation, coupled with the consistent lack of sensitivity to pause length across the conditions, points to a possibility that the participants' delayed credibility judgments were primarily based on remembered intonation of the utterances, rather than interpreted FOAK judgment. Experiment 3 followed up this possibility.

\section{EXPERIMENT 3}

Experiment 3 directly examined participants' ability to judge whether an utterance was made with rising/falling intonation following a short or long pause with a twoalternative forced choice memory judgment. Our primary interest here was two issues related to participants' memory of intonation. First and most important, the results of Experiment 2 indicated that participants' delayed credibility judgments may be based primarily on remembered intonation of the utterances. If so, the participants, across the three study conditions, should be able to remember intonation when tested more directly. Second, Experiment 2 showed only a small effect of the study condition on the participants' sensitivity to intonation. This small effect could be explained by the difference in the participants' 
memory of specific intonational features of the answering responses, with better memory of intonational features in the FOAK condition than in the paraphrasing or no-task condition. Therefore, we predicted that the participants' memory of intonation would be better in the FOAK condition than in the other two conditions when tested more directly. As for the memory of pause length, given that the participants' delayed credibility judgments did not reflect pause length, we did not advance any particular prediction, except that the participants' memory of pause should be poorer than their memory of intonation and, perhaps, no different from chance level.

We used two-alternative forced choice recognition, as opposed to yes-no recognition, in this experiment for the following reason. People are known to use more systematic and effortful processing in making a memory-based judgment when performing this type of multiple option forced choice judgment task than when performing a similar judgment in yes/no recognition format (D. S. Lindsay \& Johnson, 1989; Zaragoza \& Koshmider, 1989; for a discussion of the effect of task format on source monitoring and recognition memory, see Johnson et al., 1993). Hence, forced choice recognition tasks more effectively simulate the hypothesized process (i.e., explicit recollection of paralinguistic features in the making of delayed credibility judgments of remembered utterances) of the participants in Experiment 2.

\section{Method}

Participants. The participants were 54 native English speakers. Some of them were recruited by flyers posted on campus at New School University, and others through an ad posted on a free Internet site. None of the participants had participated in Experiment 1 or 2. The participants received a payment of $\$ 6$ each for participation. They were randomly assigned to the three study conditions.

Design and Materials. The manipulation of the independent variables was identical to that in Experiment 2. Eighteen participants were assigned to each of the three study conditions. The stimulus materials were exactly the same as the ones used in Experiment 2. For the test phase of the experiment, we presented a two-alternative forced choice auditory memory judgment test. The 24 questionanswer exchanges, as well as two practice sequences, were paired with 26 foils. For half of the foils, the answer was the same as the original, except that the pause length differed from the original; for the other half, the difference between the foils and the targets involved a difference in intonation. For example, an original questionanswer sequence with a rising answer following a short pause was paired with the same sequence with a falling answer following a short pause, to test the participants' memory of the intonation. Alternatively, the same sequence was paired with a rising answer following a long pause, to test the participants' memory of pause length. Thus, of the 24 test items, half tested memory of pause length, and the other half tested memory of the intonation.

The stimulus material was divided into a practice block with 2 two-alternative forced choice auditory memory judgment tests and two test blocks with 12 two-alternative probes each. For each forced choice memory judgment test, one of the question-answer sequences was presented auditorily, followed immediately by the alternative.

For each question-answer exchange in the original material, there were four possible configurations of pause length and intonation (long-pause-rising, long-pause-falling, short-pause-rising, and short-pause-falling). For each of these possible configurations, there were two possible pairings with foils in the recognition test.
For example, if the original material had a long pause and a rising intonation, the foil could have a short pause and a rising intonation or a long pause and a falling intonation. These pairings would produce a total of eight possibilities for each original question-answer sequence. The order of the items in a recognition test also varied (the foil first and then the target or vice versa). Thus, we constructed 16 different sets of two-alternative forced choice recognition tests. The 16 auditory recognition tests were randomly assigned to 18 participants in each study condition.

Procedure. The participants were tested individually. The presentation phase was identical to that in Experiment 2. The test phase began immediately after the completion of the presentation phase. For the two-alternative forced choice auditory memory judgments, the participants needed to indicate which of the two items (A or B) they had heard earlier in the experiment. The presentation order of the test items within each block was randomized within a block, whereas the test blocks were presented in the same order as the stimulus presentation. The participants read the instructions in the presence of the experimenter. The instructions explicitly stated the following: (1) The contents of the pairs were exactly the same; (2) a pair of question-answer exchanges differed in the way in which the respondent answered the question; (3) the participants could listen to a pair up to two times, by pressing the "R" key, before making the decision. After the instructions, the experimenter left the room to let the participants perform the task alone. After the test, the participants were paid, debriefed, and dismissed.

\section{Results and Discussion}

Table 2 shows the participants' hit rates in the intonation and pause tests in the three study conditions. First, we analyzed whether the participants' memory judgments for intonation and pause length were above chance level. Chance level was set at .5, which is conservative. A chance level of .5 for surface feature memory in this task was based on the premise that participants remember the target item $100 \%$ of the time. However, data from Experiment 2 indicated that item memory (yes response to the target items) was not perfect and depended on the study condition. Thus, the chance level performance, after adjusting for the failure to remember the items themselves, would be slightly lower than .5 .

One-sample $t$ tests indicated that the participants' hit rates for intonation judgment were significantly higher than chance in the FOAK $\left[t_{1}(17)=5.361, p<.001\right.$; $\left.t_{2}(23)=8.344, p<.001\right]$ and paraphrase $\left[t_{1}(17)=2.628\right.$, $\left.p<.05 ; t_{2}(23)=2.154, p<.05\right]$ conditions. In the notask condition, the performance was significantly above chance $\left[t_{1}(17)=2.718, p<.05\right]$ by participants, but not by items $\left[t_{2}(23)=1.633, p=.116\right]$, indicating that the effects do not generalize beyond the current items. In contrast, the participants' pause length recognition was no dif-

Table 2

Proportions of Hit Responses in the Two-Alternative Forced Choice Auditory Memory Judgments of Surface Features of Answers in the Three Study Conditions

\begin{tabular}{|c|c|c|c|c|c|c|}
\hline \multirow[b]{3}{*}{ Test } & \multicolumn{6}{|c|}{ Study Condition } \\
\hline & \multicolumn{2}{|c|}{ FOAK } & \multicolumn{2}{|c|}{ Paraphrase } & \multicolumn{2}{|c|}{ No Task } \\
\hline & $M$ & $S D$ & $M$ & $S D$ & $M$ & $S D$ \\
\hline Intonation & .70 & .16 & .57 & .12 & .57 & .10 \\
\hline Pause & .56 & .13 & .50 & .14 & .55 & .15 \\
\hline
\end{tabular}


ferent from chance level, except for the FOAK condition, in which the score was marginally above chance $\left[t_{1}(17)=\right.$ $1.77, p=.095]$ by participants, but not by items $\left[t_{2}(23)=\right.$ $1.39, p=.178]$.

Next, we analyzed the effect of study condition on the participants' memory for intonation and pause length. A 3 (study condition) $\times 2$ (test type) ANOVA on the recognition scores indicated that overall memory judgment performance differed significantly across the conditions $\left[F_{1}(2,51)=4.33, M S_{\mathrm{e}}=0.058, p<.05 ; F_{2}(2,46)=8.35\right.$, $\left.M S_{\mathrm{e}}=0.0294, p<.01\right]$ and the test types $\left[F_{1}(1,51)=\right.$ $10.90, M S_{\mathrm{e}}=0.0156, p<.01 ; F_{2}(1,23)=10.90, M S_{\mathrm{e}}=$ $0.0364, p<.01]$. Also, there was a marginal interaction between study condition and test type by participants $\left[F_{1}(2,51)=2.57, M S_{\mathrm{e}}=0.0156, p=.086\right]$, but not by items $\left[F_{2}(2,46)=1.64, p=.205\right]$. A post hoc analysis indicated that whereas the participants' intonation judgments were significantly better in the FOAK condition than in the paraphrase condition $\left[F_{1}(1,35)=7.70, M S_{\mathrm{e}}=\right.$ $0.0197, p<.01 ; F_{2}(1,23)=14.77, M S_{\mathrm{e}}=0.01828$, $p<.01]$, their performances did not differ between the paraphrase and the no-task conditions $\left[F_{1}(1,35)<1\right.$; $\left.F_{2}(1,23)<1\right]$.

These analyses indicate that study condition influenced the participants' memory of intonation, but not of pause length. A focus on FOAK induced by the study instructions brought about an improvement to intonation memory, relative to the other two study conditions. One might argue that this contrast between intonation and pause memory might be attributed to the task itself, in that when asked to make a recognition judgment, the participants might have focused on intonation, rather than on pause. However, this interpretation is unlikely, for the following three reasons. First, the instructions explicitly notified the participants that the two alternatives always differed in some way, despite the fact that the content of the two options were exactly the same. Second, even if they were initially inclined to focus on intonation, they would quickly realize that the two utterances did not differ along this dimension. With a second listening, they would clearly seek other possible distinctions. Finally, debriefing after the experiment revealed that the participants were generally aware that the difference sometimes involved pause length. For these reasons, the participants' failure to identify items with correct pause length is unlikely to be attributable to the participants' inattention to the pause length when performing the forced choice recognition task.

Overall, the results are consistent with our predictions: (1) Participants remember intonational features of answering response relatively consistently across the three conditions, (2) memory of the intonation is better in the FOAK condition than in the other two conditions, and (3) memory of pause is much poorer than memory of intonation; indeed, there is no evidence that participants can judge pause length of the heard exchanges above chance level.

In addition, we analyzed the participants' performances on intonation tests in order to probe whether there was a response bias to judge remembered information as hav-
Table 3

Proportions of Hit Responses to Items With Rising/Falling Intonation

\begin{tabular}{|c|c|c|c|c|c|c|}
\hline \multirow[b]{3}{*}{ Intonation } & \multicolumn{6}{|c|}{ Study Condition } \\
\hline & \multicolumn{2}{|c|}{ FOAK } & \multicolumn{2}{|c|}{ Paraphrase } & \multicolumn{2}{|c|}{ No Task } \\
\hline & $M$ & $S D$ & $M$ & $S D$ & $M$ & $S D$ \\
\hline Rising & .60 & .29 & .55 & .18 & .48 & .23 \\
\hline Falling & .81 & .13 & .61 & .26 & .66 & .23 \\
\hline
\end{tabular}

ing either falling or rising intonation. Table 3 reports the participants' intonation judgment performance separately for items with falling and rising intonations. There were 2 participants ( 1 in the paraphrasing condition and 1 in the no-task condition) who chose only the falling intonation response throughout the test. We excluded these participants from this analysis, because these participants' data might have unreasonably biased the results of this finegrained analysis. On the other hand, we did not exclude them from the overall analysis, because their pattern of responses may have reflected their memory problems, rather than a failure to make an effort to monitor the intonational pattern of the utterance. When we reanalyzed the overall data, by excluding those of these 2 participants, we found no difference in the results.

As Table 3 indicates, there was a clear difference in the participants' performance for answers with rising and falling intonations. A 2 (rising vs. falling intonation) $\times 3$ (study condition) ANOVA was performed on the participants' judgment performance for intonation. We did not perform item-based analysis here, because of the small number of items (six items). The analysis indicated that the participants were more likely to remember correctly falling intonations than to remember rising intonations $\left[F(1,49)=8.29, M S_{\mathrm{e}}=0.06717, p<.01\right]$. The interaction between study condition and intonation was not significant $[F(2,49)<1]$, indicating that the participants, across the three conditions, tended to judge a remembered answer as having a falling intonation when, in fact, it was spoken with a rising intonation, but not the other way around.

\section{GENERAL DISCUSSION}

\section{Delayed Credibility Judgments Based on Pauses}

Experiment 1 replicated Brennan and Williams's (1995) results on the effect of pause length. Because our study used question-answer exchanges with more content information, which have a potential influence on participants' FOAK judgments, our results bolster the claim that a pause length before an answer is a salient cue for estimating the speaker's credibility.

However, Experiment 2 indicated that pause length was not a key determiner in the participants' delayed credibility ratings of information remembered from exchanges. Experiment 3 further indicated that the lack of sensitivity to the pause length after the delay might be due to the participants' failure to retain pause length in memory. The overall trend indicates that pauses are extremely difficult 
to remember or, at least, much more difficult to remember than intonation.

We need to interpret this result cautiously. People may be more sensitive to pause length if the pauses are a consequence of natural speech, rather than electronically manipulated. Pause length in natural speech interacts with other features of utterances, such as relative word duration, fundamental frequency, and the intensity of the stressed vowel of the lengthened word. Also, unlike the unfilled pauses used in the present experiment, pauses in real-life conversations are often filled with information, such as $u m$ or $u h$ (Smith \& Clark, 1993). The multitude of information that accompanies a change in pause length in naturally occurring speech may be sufficient to make pause length a salient feature for delayed credibility judgments. That being said, the present results indicate that, in some circumstances, pause length per se is not used for delayed credibility judgments.

One reason pauses per se may be difficult to remember is because they are not attended to when listeners are trying to comprehend utterances. Indeed, people may think about what is being said during the pause, thereby diverting their attention away from the pause itself. When we analyzed the influence of pause length on memory of the content, using the data collected in Experiment 2, we found that content recognition memory (hit rate) was better for items with a long pause $(M=.77, S D=.18)$ than for items with a short pause $(M=.72, S D=.17)$ $\left[F_{1}(1,57)=4.91, M S_{\mathrm{e}}=0.0136, p<.05 ; F_{2}(1,23)=\right.$ $\left.5.333, M S_{\mathrm{e}}=0.0198, p<.05\right]$, suggesting that the participants were thinking about the content of the utterances during the pause, rather than paying attention to the pause itself. This finding does not contradict the results of Experiment 1 and those in Brennan and Williams (1995); the participants may have been sensitive to pause length in Experiment 1 and in Brennan and Williams because neither of these experiments required the participants to comprehend the utterance. The possibility that listeners do not process pause length when their interest is in the content of speech needs to be explored in future research.

\section{Delayed Credibility Judgments Based on Intonation}

Experiments 1 and 2 together showed that the participants continued to be sensitive to intonation when assessing the credibility of remembered information after a delay. This result could have arisen because the listeners recalled either (1) previously made credibility judgments or (2) a memory of the intonation.

Experiment 1 indicated that the listeners were sensitive to both pause length and intonation in immediate FOAK judgments. At that time, they may have encoded (1) the estimation of FOAK on the basis of both pause length and intonation, (2) specific information about pause length, (3) specific information about intonation, or (4) some combination of the above. If the participants relied on stored "estimation" of FOAK when assessing the credibility of remembered information in Experiment 2, their rating should have incorporated the sensitivity to pause length found in Experiment 1. But the results of Experiment 2 indicated no evidence for the participants' sensitivity to pause length and clear evidence for the participants' sensitivity to intonation in the delayed credibility judgments across the three study conditions. This pattern of results suggests that memory of intonation is likely to be the primary source of the delayed credibility judgments.

This account is further bolstered by the results of Experiment 3, which showed above-chance recognition for the intonational features of the original utterances across the three conditions and the decline in recognition for intonation in the paraphrase and no-task conditions, a pattern that closely mirrors the results of Experiment 2 . Finally, the clear sensitivity to intonation, coupled with the unpredicted reversed effect of pause length in the no-task condition in Experiment 2, makes it difficult to interpret the results without postulating the notion that memory of intonation is the primary source of delayed credibility judgments in this condition.

This argument rests partly on the null effect of pause length in Experiment 2. In addition, the participants may sometimes have performed delayed credibility judgments in different ways. The unpredicted reversed effect of pause length in the no-task condition in Experiment 2, for example, may signal the presence of diverse strategies, such as intuition or judgments about the importance of the information being conveyed. Thus, we cannot rule out the possibility that memory of FOAK judgments, either alone or in combination with uninterrupted memory of intonation, may sometimes be behind delayed credibility judgments. Future studies should try to separate the effect of these two strategies on delayed credibility judgments with more rigorous methods.

Our argument about the effect of memory of intonation in delayed credibility judgments is not concerned with the question of whether the memory of intonation that lies behind the delayed credibility judgment is an unanalyzed acoustic form in full detail or more abstract, categorically identified prosodic information (e.g., label of rising intonation; Speer et al., 1993). In Speer et al.'s study, retention of prosodic information in sentence memory was measured in the form of contextual facilitation of the prosody (implicit memory), and thus, their study can be assumed to have more directly tapped into the retention of perceptual details of prosodic information.

In contrast, Experiments 2 and 3 in the present study involved some degree of explicit/conscious recollection of the prosodic information. Experiment 2, for instance, required the participants to base their credibility judgment on written paraphrases, rather than on a repetition of what they had originally heard. This shift in perceptual format essentially ensures that participants are more likely to rely on explicit, rather than implicit, memory. Similarly, making a judgment on which of two question-answer exchanges differing in intonation is the one presented earlier (Experiment 3) requires some degree of conscious recollection of the original intonation (Jacoby, 1991; Johnson et al., 1993). Even though the decision process in Experiment 3 may have been influenced by some automatic 
or unconscious influence of the memory, it is not clear whether this type of automatic influence is directly related to perceptual implicit memory (Jacoby, 1991; Yonelinas, 2002). In other words, memory of intonation in the delayed credibility judgments in Experiment 2 and forced choice recognition for the intonation of the original utterance (Experiment 3 ) are assumed to involve some degree of active reconstruction. Thus, our measures cannot effectively separate the effect of unanalyzed acoustic memory and the effect of reconstruction based on the abstract label of rising or falling intonations.

Hence, our results might have been significantly influenced by this active reconstruction based on categorically identified prosodic information (e.g., falling or rising). This might be one of the reasons why our results differ from Speer et al.'s (1993) findings in at least two respects. First, in comparison with Speer et al.'s finding, which showed robust memory of prosody, the present study shows that memory of intonation is relatively poor, although still above chance. Second, whereas Speer et al.'s results indicated no significant effect of listeners' goal and discourse context, our results indicated the effect of the study condition on the participants' memory of intonation (in both Experiments 2 and 3). Yet we emphasize, once again, that abstract, categorically identified prosodic information (e.g., rising or falling) differs from its further interpreted form, such as FOAK or credibility, because the latter might incorporate other aspects of utterances (e.g., pause length or content information) relevant to the credibility of the information.

Another interesting finding is that the participants tended to remember answers as having falling intonations when, in fact, they were spoken with rising intonations, but not the other way around. This finding has important theoretical and practical implications. Theoretically, the finding might indicate the possibility that listeners' memory judgments involve some sort of heuristic, such as "assume that it was spoken with a falling intonation (default intonation) unless one clearly remembers the specific attributes of the experience that indicate otherwise." Thus, when members of a jury remember a witness's account without clearly remembering how (intonation) he or she provided the account, they might erroneously assume that the account was given in a "normal" assertive speech style. A jury's failure to remember intonation, then, might work to inflate their assessment of credibility of the remembered information, as suggested by the main effect of study condition on overall ratings (higher overall rating in the paraphrase and no-task conditions than in the FOAK condition) found in Experiment 2. Given that these findings have practical implications, it would be useful to investigate the effect of surface features on delayed credibility judgment - in particular, the nature of this bias - with a longer retention interval.

\section{FINAL COMMENTS AND CONCLUSION}

In sum, our research contributes to the research both on conversational discourse and on memory. On the one hand, the present research extends Brennan and Williams's (1995) finding to listeners' subsequent use of conversationally acquired information. Our study established that intonational features of question-answer exchanges have a small but systematic influence on listeners' delayed credibility estimation of information acquired from exchanges. Also, the findings revealed that listeners' delayed credibility judgments based on intonational features are under the influence of a systematic bias; listeners seem to have a tendency to erroneously judge remembered answering responses as having a normal and assertive intonation when they do not clearly remember the intonation of the utterances. These findings contribute to a better understanding of how surface features influence people's understanding and subsequent use of information learned from question-answer exchanges.

Also, the present finding makes a contribution to the field of memory research in two respects. First, the study extends Speer et al.'s (1993) finding on implicit memory of prosody by demonstrating explicit recollection of intonation. Our research indicates that people often can explicitly remember intonation. In particular, given that participants seem to recall intonation to make delayed credibility judgments, when they could have relied on some other information available in the memory of the content, intonation appears to be salient in a person's stored representation of an utterance. Also, importantly, our results show that participants' explicit remembrance of intonation is influenced by the ways in which the participants listen to the utterances. Second, the study also demonstrates that pauses are extremely difficult to remember, especially in comparison with intonation. These findings add important information to our understanding of how memory represents question-answer exchanges.

\section{REFERENCES}

ANDERSON, J. R. (1974). Verbatim and propositional representation of sentences in immediate and long-term memory. Journal of Verbal Learning \& Verbal Behavior, 13, 149-162.

ARnold, J. E., Fagnano, M., \& TAnenhaus, M. K. (2003). Disfluencies signal theee, um, new information. Journal of Psycholinguistic Research, 32, 25-36.

BAILEY, K. G. D., \& FErreira, F. (2003). Disfluencies affect the parsing of garden-path sentences. Journal of Memory \& Language, 49, 183-200.

BARr, D. J. (2003). Paralinguistic correlates of conceptual structure. Psychonomic Bulletin \& Review, 10, 462-467.

BolingER, D. L. M. (1989). Intonation and its uses: Melody in grammar and discourse. Stanford, CA: Stanford University Press.

Bradlow, A. R., NygaArd, L. C., \& Pisoni, D. B. (1999). Effects of talker, rate, and amplitude variation on recognition memory for spoken words. Perception \& Psychophysics, 61, 206-219.

Bransford, J. D., Barclay, J. R., \& Franks, J. J. (1972). Sentence memory: A constructive versus interpretive approach. Cognitive Psychology, 3, 193-209.

BrenNAN, S. E., \& SCHOber, M. F. (2001). How listeners compensate for disfluencies in spontaneous speech. Journal of Memory \& Language, 44, 274-296.

BrEnNAN, S. E., \& WILliams, M. (1995). The feeling of another's knowing: Prosody and filled pauses as cues to listeners about the metacognitive states of speakers. Journal of Memory \& Language, 34, 383-398.

Christenfeld, N. (1995). Does it hurt to say um? Journal of Nonverbal Behavior, 19, 171-186. 
DodD, D. H., \& Bradshaw, J. M. (1980). Leading questions and memory: Pragmatic constraints. Journal of Verbal Learning \& Verbal Behavior, 19, 695-704.

DoDSON, C. S., Holland, P. W., \& Shimamura, A. P. (1998). On the recollection of specific- and partial-source information. Journal of Experimental Psychology: Learning, Memory, \& Cognition, 24, 1121-1136.

DoDSON, C. S., \& Shimamura, A. P. (2000). Differential effects of cue dependency on item and source memory. Journal of Experimental Psychology: Learning, Memory, \& Cognition, 26, 1023-1044.

Echterhoff, G., Hirst, W., \& Hussy, W. (2005). How eyewitnesses resist misinformation: Social postwarnings and the monitoring of memory characteristics. Memory \& Cognition, 33, 770-782.

Fox Tree, J. E. (1999, July). Between-turn pauses and ums. Paper presented at satellite meeting Disfluency in Spontaneous Speech, University of California, Berkeley.

Fox Tree, J. E. (2001). Listeners' uses of $u m$ and $u h$ in speech comprehension. Memory \& Cognition, 29, 320-326.

GernsbachER, M. A. (1985). Surface information loss in comprehension. Cognitive Psychology, 17, 324-363.

Grice, H. P. (1975). Logic and conversation. In P. Cole \& J. L. Morgan (Eds.), Speech acts (Syntax and Semantics, Vol. 3, pp. 41-58). New York: Academic Press.

Holtgraves, T. (1997). Politeness and memory for the wording of remarks. Memory \& Cognition, 25, 106-116.

Hovland, C. I., LumSDaine, A. A., \& ShefField, F. D. (1949). Experiments on mass communication. Princeton, NJ: Princeton University Press.

JACOBY, L. L. (1991). A process dissociation framework: Separating automatic from intentional use of memory. Journal of Memory \& Language, 30, 513-541.

Johnson, M. K., Hashtroudi, S., \& Lindsay, D. S. (1993). Source monitoring. Psychological Bulletin, 114, 3-28.

Jungers, M. K., Speer, S. R., \& Palmer, C. (2002, November). Prosodic persistence in speech production and music performance. Paper presented at the 43rd Annual Meeting of the Psychonomic Society, Kansas City, MO.

Keenan, J. M., MacWhinney, B., \& Mayhew, D. (1977). Pragmatics in memory: A study of natural conversation. Journal of Verbal Learning \& Verbal Behavior, 16, 549-560.

Koriat, A. (2000). Control processes in remembering. In E. Tulving \& F. I. M. Craik (Eds.), The Oxford handbook of memory (pp. 333-346). New York: Oxford University Press.

Kraut, R. E. (1978). Verbal and nonverbal cues in the perception of lying. Journal of Personality \& Social Psychology, 36, 380-391.

Lindsay, D. S., \& Johnson, M. K. (1989). Eyewitness suggestibility effect and memory for source. Memory \& Cognition, 17, 349-358.

LindSAY, J., \& O'ConNell, D. C. (1995). How do transcribers deal with audio recordings of spoken discourse? Journal of Psycholinguistic Research, 24, 101-115.

MarTin, J. G. (1971). Some acoustic and grammatical features of spon- taneous speech. In D. Horton \& J. Jenkins (Eds.), The perception of language (pp. 47-68). Columbus, OH: Merrill.

Martin, J. G., \& Strange, W. (1968). The perception of hesitation in spontaneous speech. Perception \& Psychophysics, 3, 427-438.

Murphy, G. L., \& Shapiro, A. M. (1994). Forgetting of verbatim information in discourse. Memory \& Cognition, 22, 85-94.

Nelson, T. O., \& NaRENS, L. (1990). Metamemory: A theoretical framework and new findings. In G. H. Bower (Ed.), The psychology of learning and motivation: Advances in research and theory (Vol. 26, pp. 125-141). San Diego: Academic Press.

Palmer, C., Jungers, M. K., \& JusczyK, P. W. (2001). Episodic memory for musical prosody. Journal of Memory \& Language, 45, 526545.

Pitrelli, J., Beckman, M., \& Hirschberg, J. (1994). Evaluation of prosodic transcription labeling reliability in the ToBI framework. In Proceedings of the 1994 International Conference on Spoken Language Processing (pp. 123-126). Yokohama, Japan.

Reder, L. M. (1987). Selection strategy in question answering. Cognitive Psychology, 19, 90-138.

RoEDIGER, H. L., III, \& BLAXTON, T. A. (1987). Retrieval modes produce dissociation in memory for surface information. In D. S. Gorfein \& R. R. Hoffman (Eds.), Memory and learning: The Ebbinghaus Centennial Conference (pp. 349-379). Hillsdale, NJ: Erlbaum.

SCHACTER, D. L. (1987). Implicit memory: History and current status. Journal of Experimental Psychology: Learning, Memory, \& Cognition, 13, 501-518.

SCHWARTZ, B. L. (1994). Sources of information in metamemory: Judgments of learning and feelings of knowing. Psychonomic Bulletin \& Review, 1, 357-375.

SHRIBERG, E. E., \& LICKLEY, R. J. (1992). The relationship of filled-pause F0 to prosodic context. In Proceedings of the IRCS Workshop on Prosody in Natural Speech (Tech. Rep. IRCS-92-37, pp. 201-209). University of Pennsylvania, Institute for Research in Cognitive Science.

Smith, V. L., \& Clark, H. H. (1993). On the course of answering questions. Journal of Memory \& Language, 32, 25-38.

Speer, S. R., Crowder, R. G., \& ThOmas, L. M. (1993). Prosodic structure and sentence recognition. Journal of Memory \& Language, 32, 336-358.

Streeter, L. A., Krauss, R. M., Geller, V., Olson, C., \& Apple, W. (1977). Pitch changes during attempted deception. Journal of Personality \& Social Psychology, 35, 345-350.

UNDERWOOD, J., \& PEZDEK, K. (1998). Memory suggestibility as an example of the sleeper effect. Psychonomic Bulletin \& Review, 5, 449-453.

YoNELINAS, A. P. (2002). The nature of recollection and familiarity: A review of 30 years of research. Journal of Memory \& Language, 46, 441-517.

ZARAGOZA, M. S., \& Koshmider, J. W., III (1989). Misled subjects may know more than their performance implies. Journal of Experimental Psychology: Learning, Memory, \& Cognition, 118, 246-255. 


\section{APPENDIX A \\ Examples of the Stimulus Materials (Question-and-Answer Exchange)}

Practice item

The next 4 items are based on an article about a highway traffic accident.

1. Where did the accident happen? New Haven

2. How many cars were damaged in the accident? 13

3. What time of day did it happen? $10 \mathrm{am}$

[for manipulation in Experiments 2 and 3]

4. How long was the traffic suspended as the result of the accident? 5 hours

The next 12 items are based on an article about a man who was about to become a lawyer even though he has a criminal record of murder.

1. What is the first name of the man with the criminal record? James

2. Where was he originally from? Georgia

3. When did he commit the murder? 25 years ago

4. He stole money from the victim. How much did he steal? 150 dollars

5. He shot the victim to death, what part of the victim did he shoot? Head

6. What kind of a car was he driving at that time? A Ford

7. When he was arrested, he was carrying a drug with him. What was the drug? Marijuana

8. He got rid of the victim's body. Where did he get rid of it? A pond

9. He got BA while he was in prison. What was his GPA? Three point nine

10 . When did he get a law degree? 1999

11. What is the first name of his wife?

Linda

12. What is his wife's job?

Accountant

(Filler items for manipulation of study conditions in Experiments 2 and 3)

1-1. How old is he now? Fifty-one

$1-2$. What is the last name of the victim? Wells

1-3. How many years did he serve in prison? Seventeen

1-4. What was his undergraduate major? Sociology 


\section{APPENDIX B}

Examples of Recognition Probes in Experiment 2 (Items With * Are Lure Items)

The next 18 items are on dialogues based on Article 2, which is about a man who is about to become a lawyer even though he had a criminal record of murder.

1. The man's (with the criminal record) first name is James.

2. He was originally from Georgia.

3 . He committed the murder 25 years ago.

4. He stole $\$ 150$ from the victim.

5. He shot the victim's head.

6. He was driving a Ford at that time.

7. He was carrying Marijuana when he was arrested.

8. He got rid of the victim's body in a pond.

9. His undergraduate GPA was 3.9.

10. He got a law degree in 1999.

11. His wife's first name is Linda.

12. His wife is an accountant.

13. *He had an accomplice.

14. *The victim was 21 years old at that time.

15. *The weapon he used for the murder was a .38 caliber.

16. *The college from which he received a BA while he was in prison was Arizona State University.

17. *He has been married for 6 years.

18. *His wife is 55 years old now.

(Manuscript received July 29, 2004;

revision accepted for publication August 1, 2005.) 